$\longrightarrow$

Складна поведінка тіл з псевдопружніх $i$ псевдопружнопластичних матеріалів вимагає розвитку спеціальних алгоритмів розрахунку напружено-деформованого стану. У даній роботі розроблено чисельний метод підвищеної точності для вирішення багатовимірних нестаціонарних задач теорії термо-пружно-пластичності для тіл з псевдопружніх $i$ псевдопружнопластичних матеріалів. Це метод покомпонентного розщеплення, який створений на застосуванні нового виразу для двовимірних сплайн-функцій. Він дозволив підвищити на два порядки точність обчислень. За умови дотримання однакової точності обчислень з класичним кінцево-різницевим методом даний метод дозволяє ивидше отримувати результати в силу вибору більших кроків інтегрування за координатами. Це призводить до зменшення на два порядки кількість використовуваних вузлів просторової сітки, що є важливим $і$ корисним з практичної точки зору.

Побудована математична модель поведінки псевдопружнопластичних матеріалів, яка складається з рівняння теплопровідності, рівняння руху, геометричні співвідночення. При побудові фізичних співвідношень передбачалося, що деформація в точці представляється у вигляді суми пружною складової, стрибка деформачї при фазовому пере ходi, пластичної деформачї $i$ деформації, викликаної температурними змінами. У загальному вигляді сформульовані граничні і початкові умови.

Проведено експериментальне обгрунтування варіанта феноменологічної моделі поведінки матеріалу з пам'яттю форми. У цій моделі закладена можливість кількісної оцінки складних взаємодій між напруженнями, температурою, деформацією i ивидкістю навантаження матеріалу, які придатні $i$ для моделювання континуального рівня. На підставі цього вирішено якісно новий клас двовимірних нестаціонарних задач для матеріалів 3 пам'яттю форми, коли невідомі величини розшукуються у вигляді двомірних напружених сплайнів

Ключові слова: псевдопружний матеріал, фазові переходи, метод підвищеної точності, двовимірні сплайни
UDC 539.3

DOI: $10.15587 / 1729-4061.2018 .131644$

\section{DEVELOPMENT OF THE METHOD WITH ENHANCED ACCURACY FOR SOLVING PROBLEMS FROM THE THEORY OF THERMO- PSEUDOELASTIC- PLASTICITY}

\author{
A. Petrov \\ Postgraduate student* \\ E-mail: alex93203@rambler.ru \\ Y u.Chernyakov \\ Doctor of Physical and \\ Mathematical Sciences, Professor* \\ E-mail: yu.chernyakov@gmail.com \\ P. S t e bly a n ko \\ Doctor of Physical and \\ Mathematical Sciences, Professor \\ Department of Higher Mathematics \\ Dnipro State Technical University \\ E-mail: caf-vmi@ukr.net \\ K. De m ichev \\ $\mathrm{PhD} * *$ \\ E-mail: demichevk@gmail.com \\ V.H a y d u rov \\ Postgraduate student \\ E-mail: allif0111@gmail.com \\ Oles Honchar Dnipro National University \\ Gagarina str., 72, Dnipro, Ukraine, 49010 \\ **Department of Computer Science \\ Kyiv International University \\ Lvivska str., 49, Kiev, Ukraine, 03179
}

Dniprobudivska str., 2, Kamenskoye, Ukraine, 51918

*Department of Theoretical and Computer Mechanics

\section{Introduction}

Pseudoelasticity is the capability of a material at a higher temperature mode to accumulate deformations of a certain magnitude at loading and then return to its original position after unloading (through the loop of hysteresis). The basic mechanism is the inverse martensite transformation between the phases of a solid body, which can occur at room temperature. Such a transformation might be due to a change in temperature or a voltage change. The material is also characterized by the non-linear mechanical behavior, high internal damping, and high yield strength.

The list of alloys possessing shape memory (ASM), as well as pseudoelasticity, include the following: $\mathrm{Ni}-\mathrm{Ti}, \mathrm{AgCd}$, $\mathrm{AuCd}, \mathrm{CuAlNi}, \mathrm{CuSn}, \mathrm{CuZn}, \mathrm{FePt}, \mathrm{MnCu}, \mathrm{FeMnSi}, \mathrm{CoNiAl}$, CoNiGa, NiFeGa, TiPd, NiTi, NiTiNb, NiMnGa [1-7, 10].

Alloys possessing shape memory (ASM) constitute a special group of alloys with the capability to restore previous shape even after rather large deformations. If ASM is deformed plastically at low temperatures, this deformation 
can be restored by applying a relatively small increase in temperature. The underlying mechanism for such a recovery is the transformation from a martensitic phase into the original austenite phase. Martensitic transformations are generally divided into two groups, thermoelastic and non-thermoelastic.

Non-thermoelastic transformations are carried out mainly in alloys of iron and are linked to the non-mobile boundaries of the original martensite phase, fastened by constant defects, and contribute to forming a growing core.

Thermoelastic martensitic transformations are associated with the mobile boundaries between the original and martensite phases. These boundaries are capable of returning movement at a reverse transformation at the expense of the shrinking deformation of martensite plates rather than the generation of the core of the original phase, which leads to the crystallographically inverse transformation.

A key feature of ASM is the occurrence of a martensite phase transformation between the phase of austenite and different variants of the low-temperature, low-symmetric martensitic phase. Martensite transformation is essentially the shear, diffusion-free, phase transition of a solid body, which is accompanied by the formation of a core and by an increase in the martensitic phase at the expense of the original phase of austenite.

The above-described characteristics make the alloys possessing shape memory suitable for use in new designs, which defines the relevance of research. In this case, the calculation of structural elements and devices, which exploit advanced composite materials, for strength must be based on the new methods of enhanced accuracy and taking into consideration the possible phase transitions in a material.

\section{Literature review and problem statement}

The first ASM were designed in the middle of the last century; however, at present there are no strict and reliable defining patterns at the continual level required for engineering applications of materials. As noted in paper [1], the relation between the microscopic and macroscopic behavior is very complex and not yet developed to the extent required by such models. This is partly due to the rather strong dependence of mechanical response to temperature, loading rate, the range of deformation, geometry of the investigated body, thermomechanical history, the nature of the environment, as well as the interaction between these very parameters. Examples of such simulations are reported in paper [2]. Such alloys as $\mathrm{NiTi}, \mathrm{CuZnAl}, \mathrm{CuAlNi}, \mathrm{AuCd}$, and others, can restore the deformation up to $3 \%$. Other important characteristics of some of these materials are internal damping, pseudoelasticity, and a high yield strength.

A characteristic feature of the ASM material diagram at active loading is a region of perfect plasticity [7]. Similar regions occur at unloading, although at certain temperatures.

Paper [12] solved a number of stationary and non-stationary problems from the theory of thermo-elastic-plasticity. The authors applied physical correlations proposed in studies [13, 14], which describe simple and similar processes of deformation or the deformation processes along trajectories of small curvature. The thermo-viscoelastic-plastic processes of complex deformation of structures' elements were experimentally substantiated in work [15].
When solving nonstationary problems involving bodies made from pseudoelastic-plastic materials, there arises a new problem that is associated with the specification of physical equations. Paper [8] proposed a new variant of the method for the component-wise splitting of enhanced accuracy, constructed for solving the nonstationary problems from the theory of thermo-elasticity and thermo-plasticity. It was employed to solve two-dimensional and three-dimensional problems, respectively, from thermomechanics. An analysis of these papers revealed that it is possible to solve the two-dimensional problems of thermomechanics (when using a mathematical apparatus of the two-dimensional splines) without applying the splitting schemes based on geometrical properties.

The method of component-wise splitting, proposed in paper [12], is one of the most effective when solving numerically the multidimensional nonstationary problems from the theory of thermo-elastic-plasticity $[9,16]$. In a combination with representing the desired quantities in the form of spline-functions, it provides for the improvement in the accuracy of calculations by two orders of magnitude.

The advantage of a given approach is due to the fact that it is not more difficult to implement than the finite difference method. In this case, a solution is found in the form of spline functions throughout the entire determining domain, while a difference solution is sought only in the spatial grid nodes. Such an approach made it possible to increase the order of approximation, and it allows the selection of a larger grid based on coordinates compared with the finite-difference method, provided that the same calculation accuracy is attained.

\section{The aim and objectives of the study}

The aim of this study is to construct the finite difference method with enhanced accuracy for solving two-dimensional problems from the theory of thermo- pseudoelastic-plasticity. That would make it possible to improve the accuracy of solution based on coordinates by two orders of magnitude compared to the classic finite-difference method.

To accomplish the aim, the following tasks have been set:

- to derive an interpolation expression for the two-dimensional interpolation strained spline, which has the fourth order of approximation;

- to substantiate experimentally the variant of a phenomenological model of the performance of a material with shape memory.

\section{Defining correlations in the theory of thermo-elasto- plasticity}

One of the aspects in a general task on solving the non-stationary problems for inelastic bodies is the choice of defining correlations for the relationship between stresses and deformations. This choice is substantiated by its alignment with the experiment and is closely connected to the examined processes of deformation. In a general case, the values of deformations represent functions of the process of change in stresses and temperatures, which are defined by characteristics of the entire preceding process of change in the physical factors, rather than the current values only. Detailed information on this issue can be found in papers $[9,11,16]$. 
It was assumed when constructing the physical correlations that the deformation at a point is represented as the sum of the elastic component, a jump in deformation during phase transition, plastic deformation and the deformation caused by temperature changes. Upon solving the problem on the geometry of deformation trajectory, one can argue about the reliability of the employed defining correlations.

Based on the experiment on simple stretching of a sample at different fixed temperatures, the following function is constructed

$$
\sigma=F(\varepsilon,\langle\varepsilon\rangle, \mathrm{T})
$$

This equation defines the so-called instantaneous thermomechanical surface whose existence was experimentally confirmed with reasonable accuracy in paper [13].

Paper [15] experimentally confirmed with a certain degree of accuracy the independence of function (1) on the type of the stressed state for certain classes of originally isotropic materials. As a result, expression (1) can be recorded using the experimental data obtained from stretching the cylindrical samples. Specification of the defining equations comes down to assigning the instantaneous thermomechanical surface. Typically, while solving numerically, the equation of instantaneous thermomechanical surface of form (1) can be assigned as a table of experimental data $(\sigma)_{i},(\varepsilon)_{i}, i=0,1, \ldots, N$ at the fixed temperature values.

Fig. 1 shows typical stress-deformation dependence charts, which are derived from experiments. Fig. $1 a$ depicts a typical diagram for a construction material. Fig. $1 b$ shows a diagram with the horizontal area, which is typical for the pseudoelastoplastic alloy.

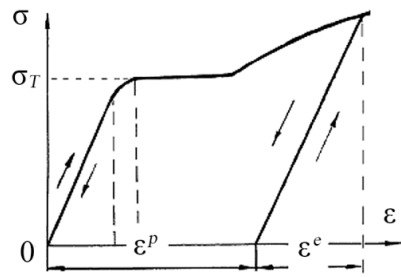

$a$

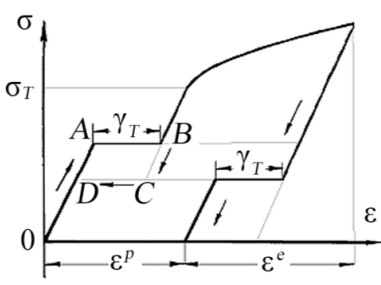

b
Fig. 1. Diagram of a material: $a-$ diagram of the construction material; $b$-diagram of the pseudoelastoplastic alloy

Each of the shown diagrams has an initial linear section $O A$. Deformation processes along it are reversible. An increase and decrease in the stress proceeds along a single straight line; in this case, the deformations are small. The yield limit depends on temperature and is defined by the coordinate of point $a$. At points $A, B, C, D$, deformations are assigned as a percentage, stress - in Gpa.

Table 1 gives experimental data obtained in papers [3, 4].

If we unload the sample at the stress that corresponds to point $\mathrm{C}$ in the diagram, part of deformation (an elastic component of the overall deformation of the model) will disappear. Segment $A B$ for the pseudoelastoplastic alloys will disappear in a jump as well, and the deformation that remains is called plastic deformation.

Thus, the complete deformation tensor can be represented in the form

$$
\hat{\varepsilon}=\hat{\varepsilon}_{e}+\hat{\gamma}_{T}+\hat{\varepsilon}_{p}+\hat{\varepsilon}_{\Theta}
$$

Table 1

Dependence of diagrams of pseudoelastic material on temperature

\begin{tabular}{|c|c|c|c|c|}
\hline $\mathrm{T},{ }^{\circ} \mathrm{C}$ & $\mathrm{A}(\varepsilon, \sigma)$ & $\mathrm{B}(\varepsilon, \sigma)$ & $\mathrm{C}(\varepsilon, \sigma)$ & $\mathrm{D}(\varepsilon, \sigma)$ \\
\hline 100 & $1.00 ; 0.82$ & $6.50 ; 0.82$ & $6.05 ; 0.45$ & $0.55 ; 0.45$ \\
\hline 90 & $1.00 ; 0.78$ & $6.50 ; 0.78$ & $6.03 ; 0.41$ & $0.53 ; 0.41$ \\
\hline 80 & $1.00 ; 0.67$ & $6.50 ; 0.67$ & $6.07 ; 0.38$ & $0.57 ; 0.38$ \\
\hline 70 & $1.00 ; 0.59$ & $6.30 ; 0.59$ & $5.81 ; 0.30$ & $0.51 ; 0.30$ \\
\hline 60 & $1.00 ; 0.44$ & $6.20 ; 0.44$ & $5.72 ; 0.23$ & $0.52 ; 0.23$ \\
\hline 50 & $1.00 ; 0.42$ & $5.80 ; 0.42$ & $5.16 ; 0.15$ & $0.36 ; 0.15$ \\
\hline 40 & $1.00 ; 0.39$ & $5.70 ; 0.39$ & $4.88 ; 0.07$ & $0.18 ; 0.07$ \\
\hline
\end{tabular}

We denote

$$
\hat{\gamma}_{T}=\gamma_{T} \frac{\partial f_{\gamma}}{\partial \hat{\sigma}}, \quad \dot{\hat{\varepsilon}}_{p}=\dot{\lambda} \frac{\partial f_{p}}{\partial \hat{\sigma}}, \quad \hat{\varepsilon}_{\Theta}=\alpha\left(T-T_{0}\right),
$$

where functions

$$
f_{\gamma}(\hat{\sigma})=0, \quad f_{p}(\hat{\sigma})=0,
$$

which, respectively, assign the boundaries of surfaces in the space of stresses. When passing through surface $f_{\gamma}(\hat{\sigma})=0$, the elastic deformation abruptly increases, and when passing through surface $f_{p}(\hat{\sigma})=0$, a body undergoes plastic deformation.

Fig. 1 also shows the elastic unloading of the sample along straight line $C D$, which is accepted to be parallel to line $O A$. Such an assumption about the unloading mechanism represents only generally the actual pattern in the deformation of a material at small deformations. At larger deformations (10\% and larger), the unloading of a sample would be non-linear.

When solving the nonstationary problems, physical correlations are reduced to the form

$$
\dot{\sigma}_{i j}=a_{i j k l} \dot{\varepsilon}_{i j}-\delta_{i j}\left[K \alpha_{T}+\theta \frac{\partial\left(K \alpha_{T}\right)}{\partial T}\right] \dot{T},
$$

where $i, j, k, l=1,2,3$, as well as the Kronecker symbol and the constants of a material for the elastic case which, in the case of a pseudoelastic behavior of the material, depend on the jump in deformation during phase transition and may depend on the deformation process parameters in the case of plastic deformations [12].

\section{The method with enhanced accuracy based on the interpolation expression for a two-dimensional spline}

The main problem in the nonstationary theory of thermo-elasto-plasticity is determining the displacement velocities and the components of stress and deformation tensors. They arise in a three-dimensional body resulting from loading and heating.

Loading process will be considered to change over time, which can start the motion of separate body parts.

The originally isotropic and homogeneous three-dimensional body $\mathrm{V}$, limited by surface $\mathrm{S}$, at the initial time is in the natural non-stressed state at an assigned temperature. 
The body is then heated and loaded with external forces. These could be the volumetric forces acting on each element of the body and the surface forces acting on one part of the body surface. At another part of the body surface, which can be fixed in a certain way, we assign the displacement velocities as functions of coordinates and time. Suppose that the heating and loading of the body proceed so that the emerging deformations can affect the temperature change in this element. We shall consider such processes of loading and temperatures levels at which the rheological properties of a material do not manifest themselves. Body configuration is specified by the equation of the surface that restricts it. In addition, it is required to assign the thermal-physical and mechanical characteristics of a body's material, as well as the conditions for its heat exchange with the environment.

Thermophysical properties of a material are characterized by coefficients of thermal conductivity and thermal diffusivity, which may depend on temperature. Heat exchange conditions are assigned in the form of appropriate boundary conditions. Mechanical characteristics of a material are assigned as the integral averaged diagrams for the stretching of samples acquired at different fixed temperatures.

In addition, one sets the values for the Poisson coefficient and a linear thermal expansion coefficient.

Based on the data specified, it is necessary to determine the temperature, three components of the displacement velocity vector, six stress tensor components and six components of the deformation tensor. Therefore, we are to determine 16 unknown time functions and functions of three coordinates. To this end, one must employ the equations of motion, geometrical and physical equations, as well as the thermal conductivity equation. These equations are solved under certain initial and boundary conditions. The initial conditions are defined for all the unknowns.

Upon determining a temperature field for different points in time, we find components of the displacement velocity vector and components of the stress and deformation tensors. We shall determine these unknowns in the following way. The basic unknowns are accepted to be the three components of the displacement velocity vector and six components of the stress tensor, for which we directly formulate the boundary conditions. In this case, we exclude from six physical equations, by applying the Cauchy geometric correlations, all deformation tensor components, which are then determined based on the known constituents of the displacement velocity vector.

As follows from paper [9], the basic methods for solving the non-stationary problems from the theory of thermo-elastic-plasticity are the difference method, the finite element method, the method of splitting based on geometrical properties.

In the framework of the difference method and the finite element method, solving a non-stationary problem from the theory of thermo-elastic-plasticity comes down to solving the systems of algebraic equations. This system is built according to the classical scheme when one replaces differential operators of the complete system of equations with their difference analogs.

Depending on the type of physical correlations that connect stress, deformation and temperature, there are various variants of these methods. Paper [12] applied a variant of the method of component-wise splitting of enhanced accuracy, developed for solving the non-stationary problems of the theory of thermo-elastic-plasticity. The original system of equations was replaced with an equivalent system of three one-dimensional equations. The basic unknowns are the velocities of displacement, stress, deformation, and temperature. If necessary, the displacements are determined by integration. In this case, the complete system is reduced to form

$$
\frac{\partial \vec{W}}{\partial t}=\sum_{i=1}^{3} A_{i} \frac{\partial \vec{W}}{\partial \theta_{i}}+\vec{B}
$$

where $\vec{W}$ is the vector whose components are the displacement velocities, components of the stress and deformation tensors.

Subsequently, within the framework of the method of component-wise splitting, system (2) and the thermal conductivity equation is replaced with the equivalent systems of three one-dimensional equations. To this end, one introduces the time grid for consideration, with respect to a fractional step. A solution to the preceding equation is employed as the initial condition for the next one.

The original non-stationary spatial problem in the form (2) could be also reduced to a system of three sequentially solved two-dimensional problems based on fractional steps in time (the Peaceman, Rachford, Douglas scheme). To build a solution to the complete system (2), we shall employ two-dimensional strained splines. Unknown magnitudes are sought in the form of a linear combination of two-dimensional splines [12].

$$
W_{m}(\xi ; \eta)=\sum_{l-1}^{2} \sum_{n-1}^{2} b_{i+l, j+n} S_{2 D}(\xi ; \eta) .
$$

Here, for example, for the first equation in the scheme of variable directions

$$
\begin{aligned}
& \xi=\frac{1}{h_{1}}\left(\alpha-\alpha_{i}\right), \quad \eta=\frac{1}{h_{2}}\left(\beta-\beta_{j}\right), \\
& \alpha \in\left[\alpha_{i}, \alpha_{i+1}\right], \quad \beta \in\left[\beta_{j}, \beta_{j+1}\right] .
\end{aligned}
$$

For the second and third vector equation of the split system, dimensionless coordinates are similarly derived. $h_{1}, h_{2}$, $h_{3}$ denote the integration steps based on coordinates.

Note that in an ideal elastoplastic environment, in the case of smooth and piecewise-smooth yield surfaces, there may exist the nonstationary displacement velocity discontinuity surface. At these surfaces, the stresses are continuous while the components of plastic deformation are disrupted. The components of displacement velocities, normal to the break surfaces, are continuous, and the surface itself coincides with the surface of maximum rate in the plastic shift. Such discontinuity surfaces can exist only under condition when the stressed state is reduced to the condition for plasticity of the maximum shear stress.

Stationary surfaces of the displacement velocity discontinuity cannot exist in ideal elastoplastic bodies [11]. A characteristic feature in the diagram of ASM material at its active loading is the section of perfect plasticity. Similar sections are observed at unloading as well, although at certain temperatures. This circumstance makes it possible, when solving the static problems of thermomechanics, to employ the methods that are used in order to solve the non-stationary problems.

In each auxiliary domain, a two-dimensional strained spline is derived in the form 


$$
\begin{aligned}
& S_{2 D}=\left[a_{0}+a_{1} \xi+a_{2} \operatorname{sh}(\sqrt{2} \xi)+a_{3} c h(\sqrt{2} \xi)\right] \times \\
& \times\left[b_{0}+b_{1} \eta+b_{2} \operatorname{sh}(\sqrt{2} \eta)+b_{3} c h(\sqrt{2} \eta)\right]
\end{aligned}
$$

where

$$
\xi \in[0 ; 1], \quad \eta \in[0 ; 1],
$$

and to determine the magnitudes $a_{i}, b_{i}, i=0 ; 1 ; 2 ; 3$,we use docking conditions. Surface (4) is symmetrical relative to the coordinate axes and consists of sixteen parts of three types. It should be noted that in an arbitrary cross section, a line is automatically built, corresponding to the one-dimensional strained spline reported in paper [12].

For a corner region, these conditions at the vertices of square $A(0 ; 0), B(0 ; 1), C(1 ; 0), D(1 ; 1)$ take the form

$$
\begin{aligned}
& S_{2 D}(0 ; 0)=0, \quad \frac{\partial S_{2 D}(0 ; 0)}{\partial \xi}=0, \quad \frac{\partial S_{2 D}(0 ; 0)}{\partial \eta}=0, \\
& S_{2 D}(0 ; 1)=0, \quad \frac{\partial S_{2 D}(0 ; 1)}{\partial \xi}=0, \quad \frac{\partial S_{2 D}(0 ; 1)}{\partial \eta}=0, \\
& S_{2 D}(1 ; 0)=0, \quad \frac{\partial S_{2 D}(1 ; 0)}{\partial \xi}=0, \quad \frac{\partial S_{2 D}(0 ; 0)}{\partial \eta}=0, \\
& S_{2 D}(1 ; 1)=W_{D}, \quad \frac{\partial S_{2 D}(1 ; 1)}{\partial \xi}=W_{D}^{\prime}, \quad \frac{\partial S_{2 D}(1 ; 1)}{\partial \eta}=W_{D}^{\prime}
\end{aligned}
$$

The right sides contain the value of the function or its derivatives. Satisfying these conditions, taking into consideration the symmetry of surface (4) relative to the diagonal, we obtain

$$
\begin{aligned}
& S_{2 D}=\left[k_{0}(1-c h \sqrt{2} \xi)+k_{1} \xi+k_{2} s h \sqrt{2} \xi\right] \times \\
& \times\left[k_{0}(1-c h \sqrt{2} \eta)+k_{1} \eta+k_{2} s h \sqrt{2} \eta\right],
\end{aligned}
$$

where

$$
k_{0}=-0,57235 ; k_{1}=-0,37114 ; k_{2}=0,26244 .
$$

For the central subdomain, conditions at the vertices of square $D(0 ; 0), N(0 ; 1), F(1 ; 0), M(1 ; 1)$ take the form:

$$
\begin{aligned}
& S_{2 D}(0 ; 0)=W_{D}, \quad \frac{\partial S_{2 D}(0 ; 0)}{\partial \xi}=W_{D}^{\prime}, \quad \frac{\partial S_{2 D}(0 ; 0)}{\partial \eta}=W_{D}^{\prime}, \\
& S_{2 D}(0 ; 1)=W_{F}, \quad \frac{\partial S_{2 D}(0 ; 1)}{\partial \xi}=W_{F}^{\prime}, \quad \frac{\partial S_{2 D}(0 ; 1)}{\partial \eta}=0, \\
& S_{2 D}(1 ; 0)=W_{F}, \quad \frac{\partial S_{2 D}(1 ; 0)}{\partial \xi}=0, \quad \frac{\partial S_{2 D}(1 ; 0)}{\partial \eta}=W_{F}^{\prime}, \\
& S_{2 D}(1 ; 1)=W_{M}, \quad \frac{\partial S_{2 D}(1 ; 1)}{\partial \xi}=0, \quad \frac{\partial S_{2 D}(1 ; 1)}{\partial \eta}=0 .
\end{aligned}
$$

Note that the surface assigned by spline (5) is symmetrical relative to the diagonals of square $D N M F$.

Satisfying the conditions in the nodes, we obtain

$$
\begin{aligned}
& S_{2 D}=\left[n_{0}+n_{1} \xi+n_{2} s h \sqrt{2} \xi+n_{3} c h \sqrt{2} \xi\right] \times \\
& \times\left[n_{0}+n_{1} \eta+n_{2} s h \sqrt{2} \eta+n_{3} c h \sqrt{2} \eta\right],
\end{aligned}
$$

where

$$
\begin{aligned}
& n_{0}=-0.42838 ; n_{1}=2.56711 ; \\
& n_{2}=-1.39527 ; n_{3}=0.6325 .
\end{aligned}
$$

For areas that combine the corner and central regions, at the vertices of square $C(0 ; 0), D(0 ; 1), E(1 ; 0), F(1 ; 1)$ the following conditions are met

$$
\begin{aligned}
& S_{2 D}(0 ; 0)=0, \quad \frac{\partial S_{2 D}(0 ; 0)}{\partial \xi}=0, \quad \frac{\partial S_{2 D}(0 ; 0)}{\partial \eta}=0, \\
& S_{2 D}(0 ; 1)=W_{D}, \quad \frac{\partial S_{2 D}(0 ; 1)}{\partial \xi}=W_{D}^{\prime}, \quad \frac{\partial S_{2 D}(0 ; 1)}{\partial \eta}=W_{D}^{\prime}, \\
& S_{2 D}(1 ; 0)=0, \quad \frac{\partial S_{2 D}(1 ; 0)}{\partial \xi}=0, \quad \frac{\partial S_{2 D}(1 ; 0)}{\partial \eta}=0, \\
& S_{2 D}(1 ; 1)=W_{F}, \quad \frac{\partial S_{2 D}(1 ; 1)}{\partial \xi}=0, \quad \frac{\partial S_{2 D}(1 ; 1)}{\partial \eta}=W_{F}^{\prime} .
\end{aligned}
$$

We can record based on this

$$
\begin{aligned}
& S_{2 D}(\xi, \eta)=\left(m_{0}+m_{1} \xi+m_{2} \operatorname{sh} \sqrt{2} \xi+m_{3} c h \sqrt{2} \xi\right) \times \\
& \times\left[m_{4}(1-c h \sqrt{2} \eta)+m_{5}(s h \sqrt{2} \eta-\sqrt{2})\right] .
\end{aligned}
$$

Here

$m_{0}=3.78066 ; m_{1}=-10.62084 ;$

$m_{2}=7.28425 ; m_{3}=-4.31838 ;$

$m_{4}=0.19552 ; m_{5}=0.29351$.

We introduce an expression for the two-dimensional basis strained spline for the domain for determining $x \in[-2 ; 2]$, $y \in[-2 ; 2]$. Introduce four auxiliary functions:

$$
\begin{aligned}
& \phi_{k}(t)=k_{0}(1-\operatorname{ch} \sqrt{2} t)+k_{1} t+k_{2} \operatorname{sh} \sqrt{2} t, \\
& \phi_{m}(t)=m_{0}+m_{1} t+m_{2} \operatorname{sh} \sqrt{2} t+m_{3} \operatorname{ch} \sqrt{2} t, \\
& \psi_{m}(t)=m_{4}(1-\operatorname{ch} \sqrt{2} t)+m_{5}(\operatorname{sh} \sqrt{2} t-\sqrt{2}), \\
& \phi_{n}(t)=n_{0}+n_{1} t+n_{2} \operatorname{sh} \sqrt{2} t+n_{3} \operatorname{ch} \sqrt{2} t .
\end{aligned}
$$

Then the surface of each part of the normalized basis two-dimensional spline, assigned by expression (4) in a single $x, y$ coordinate system, can be described using the following functions 


$$
\begin{aligned}
& S_{01}(x ; y)=\phi_{k}(x) \cdot \phi_{k}(y), \\
& S_{02}(x ; y)=\phi_{m}(x) \cdot \psi_{m}(y), \\
& S_{03}(x ; y)=\psi_{m}(x) \cdot \phi_{m}(y), \\
& S_{04}(x ; y)=\phi_{n}(x) \cdot \phi_{n}(y), \\
& S_{05}(x ; y)=\phi_{k}(x) \cdot \phi_{k}(1-y), \\
& S_{06}(x ; y)=\psi_{m}(x) \cdot \phi_{m}(1-y), \\
& S_{07}(x ; y)=\phi_{m}(x) \cdot \psi_{m}(1-y), \\
& S_{08}(x ; y)=\phi_{n}(x) \cdot \phi_{n}(1-y), \\
& S_{09}(x ; y)=\phi_{k}(1-x) \cdot \phi_{k}(1-y), \\
& S_{10}(x ; y)=\phi_{m}(1-x) \cdot \psi_{m}(1-y), \\
& S_{11}(x ; y)=\psi_{m}(1-x) \cdot \phi_{m}(1-y), \\
& S_{12}(x ; y)=\phi_{n}(1-x) \cdot \phi_{n}(1-y), \\
& S_{13}(x ; y)=\phi_{k}(1-x) \cdot \phi_{k}(y), \\
& S_{14}(x ; y)=\psi_{m}(1-x) \cdot \phi_{m}(y), \\
& S_{15}(x ; y)=\phi_{m}(1-x) \cdot \psi_{m}(y), \\
& S_{16}(x ; y)=\phi_{n}(1-x) \cdot \phi_{n}(y),
\end{aligned}
$$

As a result, the two-dimensional spline is reduced to the form

$$
S_{2 D}(x ; y)=\sum_{k=1}^{16} b_{k} \cdot S_{k}(x ; y)
$$$$
x, y \in[0 ; 1] .
$$

Expression (10) is a classical expression for a two-dimensional spline. It can be used directly within the framework of a collocation method when solving the two-dimensional problems in thermomechanics.

In the applied problems, spline (10) is convenient to use in a slightly different form. We express the unknown spline factors $b_{k}, \quad(k=1,2, \ldots, 16)$ through the values of a certain function $w(x ; y)$ at nodes $(i / 3 ; j / 3), \quad i, j=0,1,2,3$, where

$$
w(i / 3 ; j / 3) \equiv w_{i j} .
$$

The system, based on which we find takes the following form

$$
b_{k} \cdot S_{k}(i / 3 ; j / 3)=w_{i j}(i, j=0,1,2,3) .
$$

The solution to this system is obtained analytically and after substituting expressions $b_{k},(k=1,2, \ldots, 16)$ in (10), we recorded a new interpolation expression

$$
w(x, y)=\sum_{i=0}^{3} \sum_{j=0}^{3} w_{i j} \cdot F_{i j}(x ; y),
$$

where

$$
\begin{aligned}
& F_{10}(x ; y)=\alpha_{2} S_{01}(x ; y)+\beta_{2} S_{02}(x ; y)+\beta_{5} S_{03}(x ; y)+ \\
& +\omega_{3} S_{04}(x ; y)+\alpha_{8} S_{05}(x ; y)+\beta_{8} S_{06}(x ; y)+ \\
& +\beta_{14} S_{07}(x ; y)+\omega_{5} S_{08}(x ; y)+\alpha_{12} S_{09}(x ; y)+ \\
& +\beta_{15} S_{10}(x ; y)+\beta_{12} S_{11}(x ; y)+\omega_{9} S_{12}(x ; y)+ \\
& +\alpha_{3} S_{13}(x ; y)+\beta_{9} S_{14}(x ; y)+\beta_{3} S_{15}(x ; y)+\omega_{2} S_{16}(x ; y), \\
& F_{11}(x ; y)=\alpha_{6} S_{01}(x ; y)+\beta_{6}\left[S_{02}(x ; y)+S_{03}(x ; y)\right]+\omega_{7} S_{04}(x ; y)+ \\
& +\alpha_{7}\left[S_{05}(x ; y)+S_{13}(x ; y)\right]+\beta_{7}\left[S_{06}(x ; y)+S_{15}(x ; y)\right]+ \\
& +\beta_{10}\left[S_{07}(x ; y)+S_{14}(x ; y)\right]+\omega_{6}\left[S_{08}(x ; y)+S_{16}(x ; y)\right]+ \\
& +\alpha_{11} S_{09}(x ; y)+\beta_{11}\left[S_{10}(x ; y)+S_{11}(x ; y)\right]+\omega_{10} S_{12}(x ; y) .
\end{aligned}
$$

Here

$$
\begin{aligned}
& \alpha_{1}=-1,024 ; \quad \alpha_{2}=1,854 ; \quad \alpha_{3}=0,594 ; \\
& \alpha_{4}=-1,356 ; \quad \alpha_{6}=-0,758 ; \\
& \alpha_{7}=-8,383 ; \quad \alpha_{8}=7,288 ; \quad \alpha_{11}=21,855 ; \\
& \alpha_{12}=-14,351 ; \quad \alpha_{16}=8,640 ; \\
& \beta_{1}=4,195 ; \quad \beta_{2}=-19,306 ; \quad \beta_{3}=33,330 ; \\
& \beta_{4}=-11,599 ; \quad \beta_{5}=-4,654 ; \\
& \beta_{6}=29,870 ; \quad \beta_{7}=-54,471 ; \quad \beta_{8}=20,759 ; \\
& \beta_{9}=-4,708 ; \quad \beta_{10}=-7,465 ; \\
& \beta_{11}=26,300 ; \quad \beta_{12}=-15,097 ; \quad \beta_{13}=2,864 ; \\
& \beta_{14}=-3,017 ; \quad \beta_{15}=1,891 ; \quad \beta_{16}=1,489 ; \\
& \omega_{1}=-5,204 ; \quad \omega_{2}=1,666 ; \quad \omega_{3}=9,491 ; \\
& \omega_{4}=-7,152 ; \quad \omega_{5}=36,725 ; \\
& \omega_{6}=-66,177 ; \omega_{7}=20,348 ; \quad \omega_{9}=-56,662 ; \\
& \omega_{10}=123,935 ; \quad \omega_{13}=23,181 .
\end{aligned}
$$

The remaining thirteen functions are recorded using formulae (12)

$$
\begin{aligned}
& F_{01}(x ; y)=F_{10}(y ; x), \\
& F_{02}(x ; y)=F_{10}(1-y ; x), \\
& F_{03}(x ; y)=F_{00}(x ; 1-y), \\
& F_{12}(x ; y)=F_{11}(x ; 1-y), \\
& F_{13}(x ; y)=F_{10}(x ; 1-y), \\
& F_{20}(x ; y)=F_{10}(1-x ; y), \\
& F_{21}(x ; y)=F_{11}(1-x ; y), \\
& F_{22}(x ; y)=F_{11}(1-x ; 1-y), \\
& F_{23}(x ; y)=F_{10}(1-x ; 1-y),
\end{aligned}
$$




$$
\begin{aligned}
& F_{30}(x ; y)=F_{00}(1-x ; y), \\
& F_{31}(x ; y)=F_{10}(y ; 1-x), \\
& F_{32}(x ; y)=F_{00}(1-y ; 1-x), \\
& F_{33}(x ; y)=F_{00}(1-x ; 1-y) .
\end{aligned}
$$

Formula (11) makes it possible to calculate partial derivatives based on coordinates in the regions, located directly at the boundary of a body

$$
\begin{aligned}
& x \in\left[x_{0} ; x_{1}\right], \quad y \in\left[y_{0} ; y_{1}\right], \\
& x \in\left[x_{N-1} ; x_{N}\right], \quad y \in\left[y_{M-1} ; y_{M}\right]
\end{aligned}
$$

and in the adjacent regions

$$
\begin{aligned}
& x \in\left[x_{1} ; x_{2}\right], \quad y \in\left[y_{1} ; y_{2}\right], \\
& x \in\left[x_{N-2} ; x_{N-1}\right], \quad y \in\left[y_{M-2} ; y_{M-1}\right] .
\end{aligned}
$$

In all other cells of the spatial grid, we use for this purpose a linear combination (a half sum) of respective expressions written in the adjacent regions.

\section{Numerical simulation of the behavior of a material possessing shape memory}

Consider a two-dimensional problem on the non-stationary deformation of a strip with cuts made of the alloy NiTi. The shape of a cut in a node at the edge of the plate is not discussed. The cut surface is free from stresses. Here

$$
x \in[0 ; L], y \in[-H / 2 ; h / 2], t \in[0, \infty) .
$$

At the edge with cuts $x=0$, stretching speed is zero. At the other end $x=L$, we assign the speed of stretching $v=V_{0}$. Side edges of the strip $y=-H / 2, y=H / 2$ are free from stresses.

The desired magnitudes are: displacement velocities $v_{x}$, $v_{y}$; stress velocities $\sigma_{x}, \sigma_{y}, \sigma_{x y}$; deformation velocities $\varepsilon_{x}$, $\varepsilon_{y}, \varepsilon_{x y}$, and temperature T. Determine the speed of a slow wave, at which a plastic zone propagates along strip $x \in[0 ; L]$. We shall use the finite-difference method of enhanced accuracy. System (8) in a given problem can be recorded in the following form:

$$
\frac{\partial \vec{W}}{\partial t}=A_{1} \frac{\partial \vec{W}}{\partial x}+A_{2} \frac{\partial \vec{W}}{\partial y}+\vec{B}
$$

To account for the heat released as a result of the phase transition, the temperature is derived from a solution to the thermal conductivity equation

$$
\frac{\partial T}{\partial t}=a^{2}\left(\frac{\partial^{2} T}{\partial x^{2}}+\frac{\partial^{2} T}{\partial y^{2}}\right)+W_{*} .
$$

The function designated by $W_{*}$ accounts for the release of heat in a body while moving from point $A$ to point $B$ in the diagram of a material.

We introduce grids for time and coordinates

$$
\begin{aligned}
& \omega_{t}=\left\{t_{p} ; t_{p+1}=t_{p}+\tau ; t_{0}=0 ; p=0 ; 1 ; 2 ; \ldots\right\}, \\
& \omega_{h}\left\{\begin{array}{l}
x_{i} ; x_{i+1}=x_{i}+h_{1} ; x_{0}=0 ; h_{1}=\frac{L}{n} ; i=0 ; 1 ; 2 ; \ldots n ; \\
y_{j} ; y_{j+1}=y_{j}+h_{2} ; y_{0}=0 ; h_{2}=\frac{L}{m} ; j=0 ; 1 ; 2 ; \ldots m ;
\end{array}\right\} .
\end{aligned}
$$

The estimation iterative formulae, derived based on the difference Crank-Nicholson scheme, can be recorded in the vector form as

$$
\begin{aligned}
& \hat{v}^{p+1}=\hat{v}^{p}+\frac{\tau}{2}\left[\lambda\left(\hat{\sigma}^{p}\right)+\lambda\left(\hat{\sigma}^{p+1}\right)\right], \\
& \hat{\varepsilon}^{p+1}=\hat{\varepsilon}^{p}+\frac{\tau}{2}\left[\lambda\left(\hat{v}^{p}\right)+\lambda\left(\hat{v}^{p+1}\right)\right], \\
& T^{p+1}=T^{p}+\frac{\tau}{2}\left[\mu\left(T^{p}\right)+\mu\left(T^{p+1}\right)\right]+\tau W_{*}^{p} t_{*} .
\end{aligned}
$$

These formulae, in order to simplify the notation, contain in the left side the estimated magnitude for $k+1$ iteration; in the right side, we employ the value of magnitudes from the $k$-th iteration.

For the difference operators $\lambda(\ldots), \mu(\ldots)$, which approximate the first and second derivatives based on coordinates, we apply expressions, derived from formulae (11) by direct differentiation.

Consider a series of numerical results. Here we selected $L=2 H, \quad h_{1}=h_{2}=H / 10, \quad \tau=0,001$. Divergence between the neighboring iterations at $\mathrm{k}=7$ did not exceed 0.001 .

A change in the temperature field, associated with the stressed-deformed state, caused by the release of heat during the sequence of phase transitions, is shown in Fig. 2.
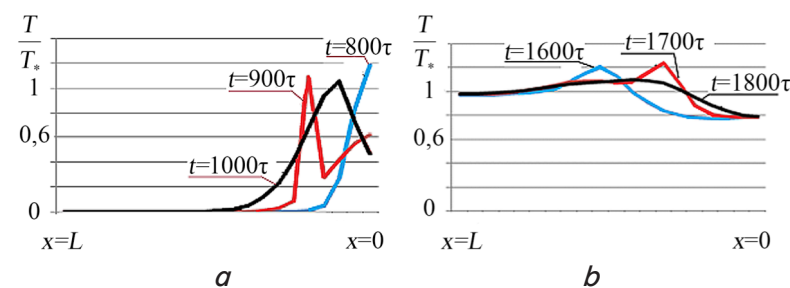

Fig. 2. Change in temperature field along the axis due to the release of heat during the sequence of phase transitions: $a$ - diagram of temperature field for time interval $800-1,000 ; b$-diagram of temperature field for time interval $1,600-1,800$

Fig. 3 shows, for the specified time points against the intensity field of plate stresses, the distribution, along the $x$ axis, of deformations (lines 1) and stresses (lines 2) at active loading.

When solving numerically, there is a transition to the dimensionless normalized magnitudes, which retained their designations

$$
\begin{aligned}
& v \Rightarrow \frac{v}{v_{*}}, \quad \varepsilon \Rightarrow \frac{\varepsilon}{\varepsilon_{S T}}, \quad \sigma \Rightarrow \frac{\sigma}{\sigma_{S T}}, \quad T \Rightarrow \frac{T}{T_{*}}, \\
& x \Rightarrow \frac{x}{x_{*}}, \quad y \Rightarrow \frac{y}{y_{*}}, \quad t \Rightarrow \frac{t}{t_{*}} .
\end{aligned}
$$


Here in the denominators we assigned the scale magnitudes for the displacement velocity, temperature, spatial coordinates, time, limits of the yield stress of a material for stress and deformation.

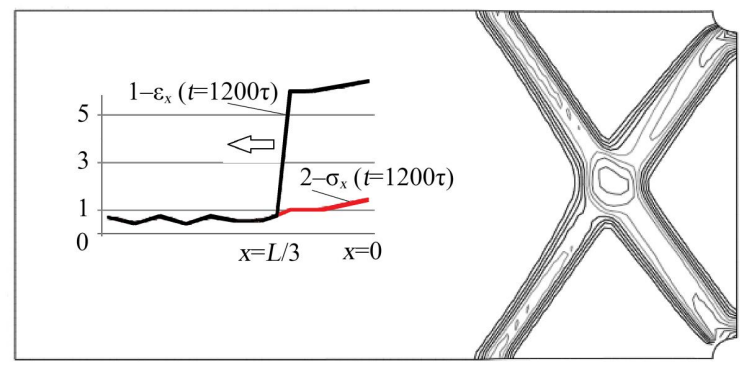

$a$

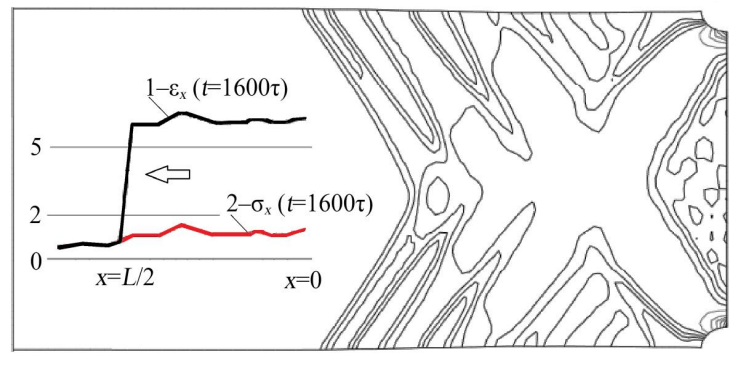

$b$

Fig. 3. Distribution of dimensionless stresses and plastic deformations for different points in time: $a$-diagram of dimensionless stresses and plastic deformations for time 1,$200 ; b$-diagram of dimensionless stresses and plastic deformations for time 1,600

The results obtained show that the front of a jump-like change in deformation propagates at constant velocity, which depends only on the mechanical properties of a material. This confirms the conclusions drawn in paper [11]. In the process of heat release caused by phase transitions the temperature distribution along the axis of the plate becomes uniform.

\section{Discussion of results on the development and application of the method with enhanced accuracy for solving the problems from the theory of thermo-elastic- plasticity}

The advantage of the developed method with enhanced accuracy for solving the multidimensional non-stationary problems from the theory of thermo-elastic-plasticity is that it expands the class of problems to be solved. It disseminates the potential possibilities of known methods on bodies fabricated from the promising pseudoelastic and pseudoelastic-plastic materials. The disadvantage of a given method is that the proposed variant applies only for composite bodies of the canonical shape.

The results reported here could prove useful in the study of the behavior of structural elements of a complex shape, which would make it possible to reduce the time for their creation, to improve reliability and efficiency, to reduce material consumption and bring down the cost. They could be applied when determining the strength characteristics of structural elements made from materials sensitive to the type of the thermo-stressed state. Based on this, it is planned to develop technological processes for fabricating the spatial and thin-walled elements of structures with enhanced mechanical characteristics. It is planned, based on the research results, to introduce grinding wheels with mineral fillers at industrial enterprises. The new technology could be exploited in industrial production and for manufacturing the grinding tools that are used in the machining of tool materials.

Note that problems on such structural elements as "hollow chamfer", "bevel", "groove" and other bodies that have the non-canonical surfaces at the boundaries of joining the transition regions, require solving additional problems. Those are the interpolation problems and the extrapolation of a solution to the problem of thermomechanics among the nodes in one or another finite-difference grid. This task was not stated in this work, but the proposed apparatus of a two-dimensional spline could be very efficient when solving it.

In the future, we plan to improve the undertaken research into development and experimental validation of new physical correlations. These correlations should take into consideration the dependence of mechanical reaction in the behavior of a body on temperature, possible phase transitions, as well as the thermomechanical history.

\section{Conclusions}

1. We derived an expression for the two-dimensional interpolation strained spline, which has the fourth order of approximation. That made it possible to improve by two orders of magnitude the accuracy of computing a solution in comparison with well-known methods. Recurrent formulae allow us to obtain, respectively, the third (for temperature) and fourth (for the velocities of displacements, stresses, and deformations) order of the method approximation based on coordinates.

2. Using the expression obtained for a two-dimensional interpolation strained spline, we developed an effective variant of the finite-difference method with enhanced accuracy. Subject to the same accuracy of calculations when using the classic finite-difference method, a given method makes it possible to obtain results faster, due to the choice of larger steps of integration based on coordinates. Thus, for the solved problem, we assigned 230 nodes in a spatial grid. To obtain a solution (with the same accuracy) employing the classic difference method would require 2,003,000 nodes. This leads to a substantial reduction in the calculation time, given only one step in time, which is $0.001 \%$ for the considered problem.

3. We have experimentally substantiated a variant of the phenomenological model for the behavior of a shape memory material. This model implies a possibility to quantify complex interactions between stresses, temperature, deformation, and the speed of loading a material, suitable for modeling at the continuum level. Based on it, we have resolved a qualitatively new class of two-dimensional non-stationary problems for materials possessing shape memory when the unknown magnitudes are sought in the form of two-dimensional strained splines. 


\section{References}

1. Abeyaratne R., Knowles J. K. Evolution of phase transitions. Cambridge University Press, 2006. 258 p.

2. Chaboche J. L. A review of some plasticity and viscoplasticity constitutive theories // International Journal of Plasticity. 2008. Vol. 24, Issue 10. P. 1642-1693. doi: https://doi.org/10.1016/j.jplas.2008.03.009

3. Chernyakov Yu. A., Polishchuk A. S. Modeling superelastic response of shape memory alloys subjected to complex loading // Advanced problems in Mechanics of Heterogeneous Media and Thin-Walled Structures. Dnipropetrovsk, 2010. P. 97-113.

4. Qiao L., Radovitzky R. Computational modeling of size-dependent superelasticity of shape memory alloys // Journal of the Mechanics and Physics of Solids. 2016. Vol. 93. P. 93-117. doi: https://doi.org/10.1016/j.jmps.2016.01.004

5. Kyriakides S., Miller J. E. On the Propagation of Lüders Bands in Steel Strips // Journal of Applied Mechanics. 2000. Vol. 67, Issue 4. P. 645. doi: https://doi.org/10.1115/1.1328348

6. Shaw J. Thermomechanical aspects of NiTi // Journal of the Mechanics and Physics of Solids. 1995. Vol. 43, Issue 8. P. $1243-1281$. doi: https://doi.org/10.1016/0022-5096(95)00024-d

7. Shaw J. A., Kyriakides S. On the nucleation and propagation of phase transformation fronts in a NiTi alloy // Acta Materialia. 1997. Vol. 45, Issue 2. P. 683-700. doi: https://doi.org/10.1016/s1359-6454(96)00189-9

8. Steblyanko P. A. The schemes of abnormally high accuracy solution of non-stationary problems of theory of the thermo-elastic-plasticity for plates and shells - Thermal Stresses and Related Topics // Proc. 5th Int. Conf. Virginia, 2003. P. 231-234.

9. Steblyanko P. A., Shevchenko Yu. N. Computational methods in stationary and non-stationary thermal-plasticity problems // Computational Methods in Stationary and Nonstationary Thermal-Plasticity. Problems, ETS-Encyclopedia of Thermal Stresses, Shpringer Verlag. 2014. Issue 7. P. 630-636.

10. Xia M., Sun Q. Thermomechanical responses of nonlinear torsional vibration with NiTi shape memory alloy - Alternative stable states and their jumps // Journal of the Mechanics and Physics of Solids. 2017. Vol. 102. P. 257-276. doi: https://doi.org/10.1016/ j.jmps.2016.11.015

11. Ivlev D. D., Bikovtsev G. I. The theory of a strengthened plastic body. Moscow: Nauka, 1971. 232 p.

12. Steblyanko P. A. Methods of decomposition in space problems of the theory of plasticity. Kyiv: Naukova dumka, 1998. 304 p.

13. Shevchenko Yu. N., Terekhov R. G. The physical equations termalviscousplasticity. Kyiv: Naukova dumka, 1982. 238 p.

14. Shevchenko Yu. N., Savchenko V. G. The mechanics of coupled fields in elements of constructions. Vol. 2. The thermo-viscous plasticity. Kyiv: Naukova dumka, 1987. 264 p.

15. Shevchenko Yu. N., Babeshko M. E., Terehov R. G. Thermoviscoelastoplastic Processes of the Combined Deformation of Structural Elements. Kyiv: Naukova dumka, 1992. 328 p.

16. Shevchenko Yu. N., Savchenko V. G. Spatial problems termalviscousplasticity: focus on the Ukrainian researches (review) // Appl. mechanics. 2016. Vol. 52, Issue 3. P. 3-70. 